\title{
The Influence of rs1859168 Polymorphism on Serum Expression of HOTTIP and Its Target miR-615-3p in Egyptian Patients with Breast Cancer
}

\author{
Omayma O. Abdelaleem ${ }^{1}$, Olfat G. Shaker ${ }^{2}{ }^{(0}$, Marwa N. AbdelHafez ${ }^{3}$, Noha K. Abdelghaffar ${ }^{4}$, \\ Hanaa M. Eid ${ }^{5, *, \dagger}$, Mohamed Zaidan ${ }^{6}$, Abeer A. Khalefa ${ }^{7}$, Naglaa A. Ahmed ${ }^{7}$, Nada F. Hemeda ${ }^{8}$, \\ Othman M. Zaki ${ }^{9}$, Aeshah Ali A. Awaji ${ }^{10}$ and Shereen R. Mohammed ${ }^{1}$
}

check for updates

Citation: Abdelaleem, O.O.; Shaker, O.G.; AbdelHafez, M.N.;

Abdelghaffar, N.K.; Eid, H.M.; Zaidan, M.; Khalefa, A.A.; Ahmed,

N.A.; Hemeda, N.F.; Zaki, O.M.; et al. The Influence of rs1859168

Polymorphism on Serum Expression of HOTTIP and Its Target miR-615-3p in Egyptian Patients with Breast Cancer. Biomolecules 2021, 11, 733. https://doi.org/10.3390/biom11050733

Academic Editor: Cecilia M. P. Rodrigues

Received: 4 April 2021

Accepted: 7 May 2021

Published: 14 May 2021

Publisher's Note: MDPI stays neutral with regard to jurisdictional claims in published maps and institutional affiliations.

Copyright: (c) 2021 by the authors. Licensee MDPI, Basel, Switzerland. This article is an open access article distributed under the terms and conditions of the Creative Commons Attribution (CC BY) license (https:// creativecommons.org/licenses/by/ $4.0 /)$.
1 Department of Medical Biochemistry and Molecular Biology, Faculty of Medicine, Fayoum University, Fayoum 63511, Egypt; ooa00@fayoum.edu.eg (O.O.A.); srk00@fayoum.edu.eg (S.R.M.)

2 Department of Medical Biochemistry and Molecular Biology, Faculty of Medicine, Cairo University, Cairo 11511, Egypt; Olfat.shaker@kasralainy.edu.eg

3 Department of Medical Oncology, National Cancer Institute, Cairo University, Cairo 11511, Egypt; marwa_nabil_25@yahoo.com

4 Department of Clinical pathology, Faculty of Medicine, Fayoum University, Fayoum 63511, Egypt; nka00@fayoum.edu.eg

5 Department of Microbiology and Immunology, Faculty of Medicine, Fayoum University, Fayoum 63511, Egypt

6 Department of General Surgery, Faculty of Medicine, Fayoum University, Fayoum 63511, Egypt; Mfz00@fayoum.edu.eg

7 Department of Physiology, Faculty of Medicine, Zagazig University, Zagazig 44523, Egypt; abeerbiomy@zu.edu.eg (A.A.K.); naahmed@nu.edu.sa (N.A.A.)

8 Department of Genetics, Faculty of Agriculture, Fayoum University, Fayoum 63511, Egypt; nfh00@fayoum.edu.eg

9 Department of Clinical Pathology, Faculty of Medicine, Damietta University, Damietta 34511, Egypt; Drosmanzaki@hotmail.com

10 Department of Biology, Faculty of Science, University College of Taymaa, Tabuk University, Tabuk 47711, Saudi Arabia; aawaji@ut.edu.sa

* Correspondence: hme11@fayoum.edu.eg; Tel.: +20-0101-154-2894

+ Present address: Medical Microbiology and Immunology, Faculty of Medicine, Fayoum University, Egypt.

Abstract: Background: Polymorphisms of long noncoding RNAs are lately documented as hazardous factors for the development of numerous tumors. Furthermore, the evaluation of noncoding RNAs has emerged as a novel detector of breast cancer patients. We aimed to genotype the HOXA transcript at the distal tip (HOTTIP) rs1859168 and assess its relationship with the levels of the serum HOTTIP and its target miR-615-3p in patients with breast cancer (BC). Methods: One hundred and fiftyone patients with BC, 139 patients with fibroadenoma (FA), and 143 healthy participants were incorporated into the current study. The genotyping of rs1859168 and the measurements of the HOTTIP and miR-615-3p levels were assessed using quantitative real-time PCR. Results: We revealed a significant association between each of the CC genotypes, $\mathrm{C}$ allele, dominant and recessive models, and the increased risk of $\mathrm{BC}(p=0.013, p<0.001, p<0.001$, and $p<0.001$, respectively) relative to the healthy controls. Similarly, the CC genotype, $\mathrm{C}$ allele, and recessive model were observed to be related to the increased incidence of BC with respect to FA ( $p<0.001$ for all). A significant upregulation of HOTTIP and a marked decrease of miR-615-3p were verified in patients with BC compared to each of the healthy individuals, patients with FA, and the non-BC group (healthy subjects + FA) $(p<0.001$ for all). A significant negative correlation was demonstrated between the expression of HOTTIP and miR-615-3p in the serum of patients with BC. The HOTTIP expression was upregulated, while that of miR-615-3p was downregulated in patients with BC who carried the CC genotype with respect to those who carried the AA or AC genotypes ( $p<0.05$ for all). Conclusions: The genetic variants of rs1859168 are linked to an increased susceptibility to BC. Moreover, HOTTIP and miR-615-3p may be used as novel indicators and targets for the treatment of patients with BC. 


\section{Introduction}

Breast cancer (BC) is considered the most frequent malignancy diagnosed among women [1]. Genetic alterations play an essential role in BC pathogenesis [2]. Most breast cancers are diagnosed at a progressive stage due to difficulties in the early detection of the disease. Therefore, detecting new biomarkers is necessary to diagnose $\mathrm{BC}$ and predict its behavior, allowing the development of new therapeutic targets [3].

Long noncoding RNAs (lncRNAs) are recognized as RNA molecules with more than 200 nucleotides in length and without a protein-coding capability [4]. Emerging evidence has recently shown that lncRNAs play an essential role in the regulation of some genes concerning the suppression of tumors or oncogenes affecting tumor initiation and progression [5].

The HOXA transcript at the distal tip (HOTTIP) is a lncRNA found at the $5^{\prime}$-end of the HOXA cluster [6]. Numerous works have revealed that HOTTIP regulates HOXA gene expression so that it may play a role in cancer pathogenesis. The upregulation of HOTTIP expression has been described in a variety of malignancies [7]. Interestingly, Yang and his colleagues also reported a positive correlation in BC between HOTTIP expression and lymph node metastasis, tumor size, and TNM staging [8].

However, the prevalence and functional significance of HOTTIP in breast cancer still requires more investigation.

Many recent researchers have revealed that single-nucleotide polymorphisms (SNPs) present in lncRNA genes affect the function and expression of those lncRNAs, representing an important risk factor of disease susceptibility [9]. Furthermore, numerous studies have explained the associations between IncRNA polymorphisms and the susceptibility to different cancers $[10,11]$. Recently, $\mathrm{Hu}$ et al. identified that the functional variant rs1859168 $(\mathrm{A} / \mathrm{C})$ in the HOTTIP regulation region contributed to the risk of pancreatic cancer [12], considering $\mathrm{A}$ as the wild allele and $\mathrm{C}$ as the mutant one. However, there were no studies that reported the associations between this SNP and $\mathrm{BC}$ risk.

MicroRNAs (miRNAs) are small noncoding RNAs (19-25 nucleotides in length). Accumulating evidence has linked miR-615-3p to many cancers, it was revealed that miR-615-3p was downregulated in hepatoma cells and breast cancer cells, as well as pancreatic ductal adenocarcinoma [13-15]. Additionally, Bai et al. verified that miR615 was significantly repressed in BC tissues and inhibited the expression of AKT2 [14]. However, little is known about its role in BC. Moreover, it was proven that HOTTIP directly targets miR-615 (as it acts as a competing endogenous RNA (ceRNA) for miR-615-3p, resulting in the activation of its endogenous targets), affecting the growth of renal cell carcinoma [16].

In the current study, we aimed to evaluate whether the rs1859168 SNP is associated with breast cancer or the development of fibro adenoma (FA). Additionally, we performed this work to find out whether this polymorphism could affect the serum expression level of HOTTIP and its target microRNA (miR-615-3p) and explore any correlations with the clinicopathological features. Furthermore, we investigated the possibility of using HOTTIP and miR-615-3p as noninvasive biomarkers of BC, analyzing the correlations between their serum expression levels and pathology, as well as the clinical data in BC.

\section{Materials and Methods}

\subsection{Subjects}

The current study included 151 BC patients who were histologically or cytologically confirmed to have BC. Additionally, 139 female patients with FA were incorporated into this study. Patients were recruited from the outpatients and inpatients of the Surgery 
Department, Faculty of Medicine, Fayoum University and from The National Cancer Institute, Cairo University during the period from December 2018 to May 2020.

Patients with a history of any other malignancies, current infectious or inflammatory conditions, or those who received any direct or specific treatments for cancer were excluded from the study.

A total of 143 healthy age-matched women who underwent a medical examination in the outpatient clinic of the Surgery Department, Faculty of Medicine, Fayoum University volunteered as the control subjects. Neither they nor their families had a history of cancer.

All the enrolled participants gave signed informed consent. Ethical approval was obtained from the Faculty of Medicine, Fayoum University Local Ethics Committee, which was in-line with the ethical guidelines of the Declaration of Helsinki.

\subsection{Blood Sample Processing}

Venous blood samples were taken from each participant. Samples were delivered into a plain vacutainer with a gel separator. The blood was allowed to clot for $15 \mathrm{~min}$, and the serum was separated by centrifugation at $4000 \times g$ for $10 \mathrm{~min}$. Serum samples were immediately stored at $-80^{\circ} \mathrm{C}$ until use. Another group of whole-blood samples was drawn in EDTA-containing tubes for the DNA extraction and genotyping of rs1859168.

\subsection{Total RNA Extraction and Reverse Transcription}

MiRNeasy extraction kit (Qiagen, Hilden, Germany) was used to get the total RNA (including microRNAs and lncRNAs) extracted from the serum samples after adding the QIAzollysis reagent following the manufacturer's protocol. The extracted RNA was determined using the NanoDrop ${ }^{\circledR}$ (ND)-1000 spectrophotometer (NanoDrop Technologies Inc., Wilmington, DE, USA).

Total RNA was reverse-transcribed using the RT2 first strand Kit (Qiagen, Maryland, MY, USA) in a whole volume of $20 \mu \mathrm{L} /$ reaction for the long noncoding RNA analysis, while the miScript II RT kit (Qiagen) was used for the miRNA analysis in a $20-\mu \mathrm{L}$ RT reaction according to the manufacturer's instructions.

\subsection{HOTTIP and miR-615-3p Detection by RT-qPCR}

RT-qPCR of the HOTTIP expression was performed using the RT2 SYBR Green PCR kit (Qiagen, Maryland, MY, USA). The expression of miR-615-3p was quantified using the miScript SYBR Green PCR kit (Qiagen, Valenica, CA, USA) following the instructions of the manufacturer. The RefSeq accession no. of HOTTIP was NR_037843.3, and the catalog number of miR-615-3p was MS00029225. All the reactions were done in the Rotor gene Q System (Qiagen) on a 20- $\mu \mathrm{L}$ reaction mixture with the following settings for the HOTTIP assessment: $95^{\circ} \mathrm{C}$ for $10 \mathrm{~min}$; subsequently, 40 cycles at $95^{\circ} \mathrm{C}$ for $15 \mathrm{~s}$ and $60^{\circ} \mathrm{C}$ for $60 \mathrm{~s}$. However, for the assessment of miR-615-3p, the cycling conditions were as follows: $95{ }^{\circ} \mathrm{C}$ for $30 \mathrm{~min}$, followed by 40 cycles at $94^{\circ} \mathrm{C}$ for $15 \mathrm{~s}, 55^{\circ} \mathrm{C}$ for $30 \mathrm{~s}$, and $70{ }^{\circ} \mathrm{C}$ for $30 \mathrm{~s}$.

The expression values of HOTTIP were normalized using GAPDH as an endogenous reference gene $[17,18]$. However, for the calculation of the miR-615-3p expression level, SNORD 68 was used as an internal control. The GAPDH primer sequences were forward $5^{\prime}$ CCCTTCATTGACCTCAACTA- $3^{\prime}$ and reverse $5^{\prime}$-TGGAAGATGGTGATGGGATT- $3^{\prime}$. The catalog number of SNORD 68 was MS00033712. The equation $2^{-\Delta \Delta C t}$ was used to calculate the fold changes (FC) of HOTTIP and miR-615-3p [19]. The FC of the healthy group was assumed as 1 .

\subsection{DNA Extraction and Genotyping}

Genomic DNA was extracted from whole blood using a Qia-amplification DNA extraction kit (Qiagen, Valenica, CA, USA) following the manufacturer's instructions. A NanoDrop ${ }^{\circledR}$ (ND)-1000 spectrophotometer (NanoDrop Technologies Inc., Wilmington, DE, USA) was used to assess the quantitation and purity of the DNA samples. The genotyping of rs1859168 (A/C) of HOTTIP (PN4351379) was performed using a predesigned TaqMan 
SNP genotyping assay (Applied Biosystems, Thermo Fisher Scientific, Foster City, CA, USA), in agreement with the instructions of the manufacturer. RT-PCR was done on a Rotor gene Q System (Qiagen, Valenica, CA, USA). The cycling conditions included denaturation for $10 \mathrm{~min}$ at $95^{\circ} \mathrm{C}, 45 \mathrm{cycles}$ at $92^{\circ} \mathrm{C}$ for $15 \mathrm{~s}$, and $60^{\circ} \mathrm{C}$ for $90 \mathrm{~s}$ for annealing and extension.

\subsection{Statistical Analysis}

The Statistical Package for Social Sciences (SPSS) version 24 (USA) was used in performing the statistical analysis. The representation of the quantitative data was done by using the mean, standard deviation (SD), standard error of mean (SEM), median, and interquartile range (IQR). For the categorical data, a chi-square test was done. Meanwhile, the continuous variables were analyzed via the Mann-Whitney $U$ test, which were presented as medians (interquartile range). Odds ratios (ORs) with $95 \%$ confidence intervals (CI) (which were age-adjusted) of alleles and genotypes frequency of rs1859168 in the studied groups were assessed using the multivariate logistic regression analysis. Nonparametric data and categorical data were compared using the chi-square test. Spearman's correlation was run to determine the correlation between HOTTIP and miR-615-3p.

Receiver operating characteristic (ROC) curve analyses were performed to conclude the sensitivity and specificity of HOTTIP and miR-615-3p as predictors in discriminating BC from other groups. $p$-values less than 0.05 were considered statistically significant.

\section{Results}

\subsection{Demographic, Clinical, and Pathological Features of the Participants}

The detailed findings of the general characteristics of the study participants in the current work are clarified in Table 1.

Table 1. Characteristics of the participants.

\begin{tabular}{|c|c|c|c|c|c|c|c|}
\hline \multicolumn{2}{|c|}{ Variables } & $\begin{array}{c}\mathrm{BC} \\
(n=151)\end{array}$ & $\begin{array}{c}\text { FA } \\
(n=139)\end{array}$ & $\begin{array}{l}\text { Control } \\
(n=143)\end{array}$ & $\begin{array}{c}p \text {-Value } \\
\text { (BC vs. control) }\end{array}$ & $\begin{array}{c}p \text {-Value } \\
\text { (BC vs. FA) }\end{array}$ & $\begin{array}{c}p \text {-Value } \\
\text { (FA vs. control) }\end{array}$ \\
\hline Age (years) & Mean \pm SD & $54.91 \pm 6.43$ & $51.08 \pm 9.73$ & $49.89 \pm 10.37$ & 0.09 & 0.341 & 0.178 \\
\hline \multirow{3}{*}{ Family history } & Yes (BC) $n(\%)$ & $94(62.25)$ & $2(1.44)$ & $1(0.70)$ & $<0.001 *$ & $<0.001 *$ & 0.19 \\
\hline & Yes (FA) $n(\%)$ & $15(9.93)$ & $11(7.91)$ & $2(1.40)$ & 0.06 & 0.09 & 0.15 \\
\hline & No $n(\%)$ & $42(27.81)$ & $126(90.65)$ & $140(97.90)$ & $<0.001^{*}$ & $0.01^{*}$ & 0.182 \\
\hline \multirow{2}{*}{$\begin{array}{c}\text { History of } \\
\text { Hypertension }\end{array}$} & Yes $n(\%)$ & $25(16.56)$ & $10(7.19)$ & $8(5.59)$ & 0.54 & 0.243 & 0.821 \\
\hline & No $n(\%)$ & $126(83.44)$ & $129(92.81)$ & 135 (94.41) & 0.214 & 0.343 & 0.88 \\
\hline \multirow{2}{*}{ History of DM } & Yes $n(\%)$ & $29(19.21)$ & $22(15.83)$ & $15(10.49)$ & 0.17 & 0.69 & 0.54 \\
\hline & No $n(\%)$ & $122(80.79)$ & $117(84.17)$ & $128(89.51)$ & 0.39 & 0.67 & 0.24 \\
\hline \multirow{3}{*}{$\begin{array}{l}\text { Menstrual } \\
\text { history }\end{array}$} & $\begin{array}{l}\text { Premenopausal } \\
\text { (regular) }\end{array}$ & $24(15.89)$ & $51(36.69)$ & 55 (38.46) & 0.09 & 0.08 & 0.401 \\
\hline & $\begin{array}{l}\text { Premenopausal } \\
\text { (irregular) }\end{array}$ & $26(17.22)$ & $41(29.50)$ & $53(37.06)$ & 0.19 & 0.06 & 0.108 \\
\hline & Postmenopausal & $101(66.89)$ & $47(33.81)$ & $35(24.48)$ & 0.06 & 0.09 & 0.28 \\
\hline \multirow{2}{*}{$\begin{array}{c}\text { Hormonal } \\
\text { Contraceptive }\end{array}$} & Yes $n(\%)$ & $103(68.21)$ & $89(64.03)$ & $67(46.85)$ & 0.13 & 0.53 & 0.18 \\
\hline & No $n(\%)$ & $48(31.79)$ & $50(35.97)$ & $76(53.15)$ & 0.49 & 0.56 & 0.27 \\
\hline \multirow{3}{*}{$\begin{array}{c}\text { Type of tumor } \\
n(\%)\end{array}$} & Invasive Duct ii & 117 (77.48) & & & & & \\
\hline & Invasive Duct iii & $28(18.55)$ & & & & & \\
\hline & $\begin{array}{c}\text { Invasive Lobular } \\
\text { Carcinoma }\end{array}$ & $6(3.97)$ & & & & & \\
\hline \multirow{2}{*}{$\begin{array}{c}\text { T Classification } \\
n(\%)\end{array}$} & $\mathrm{T} 2$ & $89(58.94)$ & & & & & \\
\hline & T3 & $62(41.06)$ & & & & & \\
\hline \multirow{3}{*}{$\begin{array}{c}\mathrm{N} \\
\begin{array}{c}\text { Classification } n \\
(\%)\end{array} \\
\end{array}$} & N1 & $22(14.57)$ & & & & & \\
\hline & N2 & $88(58.28)$ & & & & & \\
\hline & N3 & 41 (27.15) & & & & & \\
\hline $\begin{array}{c}\mathrm{M} \\
\text { Classification } n \\
(\%)\end{array}$ & Zero & $151(100)$ & & & & & \\
\hline \multirow{2}{*}{$\begin{array}{c}\text { TNM staging } n \\
(\%)\end{array}$} & II & $21(13.91)$ & & & & & \\
\hline & III & $130(86.09)$ & & & & & \\
\hline \multirow{2}{*}{$\mathrm{ER} / \mathrm{PR} n(\%)$} & Positive & $35(23.18)$ & & & & & \\
\hline & Negative & $116(67.82)$ & & & & & \\
\hline \multirow{2}{*}{$\begin{array}{c}\text { Tumor Size } n \\
(\%)\end{array}$} & $<5 \mathrm{~cm}$ & 79 (52.31) & & & & & \\
\hline & $>5 \mathrm{~cm}$ & $72(47.69)$ & & & & & \\
\hline
\end{tabular}

BC: Breast Cancer, FA: Fibroadenoma, DM: Diabetes mellitus, and ER/PR: Estrogen Receptor/Progesterone Receptor. Data are expressed as the mean $\pm(\mathrm{SD})$ or $n(\%)$. $p$-values were determined using an independent $t$-test or chi-square test as an appropriate comparison. * Significant at $p<0.05$. 
No marked differences were noted concerning the mean age among the patients with $\mathrm{BC}$ or FA when compared to the healthy group $(p>0.05)$. Similarly, no marked differences were noted regarding the ages between the $\mathrm{BC}$ and FA groups $(p>0.05)$.

Significant statistical differences were observed among the BC patients and those with $\mathrm{FA}$ and between the $\mathrm{BC}$ patients compared with the controls regarding the percentage of positive family history of $\mathrm{BC}$ (elevated in the $\mathrm{BC}$ group, $p<0.001$ for both).

Considering the clinicopathological data, $117(77.48 \%)$ of all patients presented with invasive duct carcinoma (Grade 2 ) and 28 (18.55\%) with invasive duct carcinoma (grade 3), while only six patients $(3.97 \%)$ were diagnosed with invasive lobular carcinoma. For the TNM staging, the percentage of patients with T 2 and 3 were $58.94 \%$ and $41.06 \%$, respectively, while the percentage of patients with $\mathrm{N} 1,2$, and 3 were $14.57 \%, 58.28 \%$, and $27.15 \%$, respectively. Concerning the TNM staging, most patients $(86.09 \%)$ were grade three, whereas $13.91 \%$ were grade two. Regarding the estrogen and progesterone receptors (ER/PR), 35 (23.18\%) patients were positive for ER/PR, and $116(67.82 \%)$ were negative for ER/PR. Finally, $52.31 \%$ of the tumors were smaller than $5 \mathrm{~cm}$, while $47.69 \%$ were larger than $5 \mathrm{~cm}$.

\subsection{Frequency Distribution of the Alleles and Genotypes of rs1859168 in Patients with BC, FA, and Healthy Subjects}

The distribution of the genotypes of rs1859168 in the control individuals obeyed the Hardy-Weinberg equilibrium $(p=0.570)$.

The distribution of the different genotypes and alleles of rs1859168 are shown in Table 2. Comparing BC patients with the healthy group, we revealed that the CC genotype (considering the AA genotype as a reference) was linked strongly to a high incidence of breast cancer (adjusted OR $=1.983,95 \%$ CI: 0.987-4.572, $p=0.013$ ). However, the AC genotype was significantly associated with a low incidence of BC (adjusted OR $=8.534$, 95\% CI: $2.478-17.392, p<0.001)$.

Table 2. Distribution frequency of the rs1859168 genotypes and alleles in patients with breast cancer, fibroadenoma, and healthy subjects.

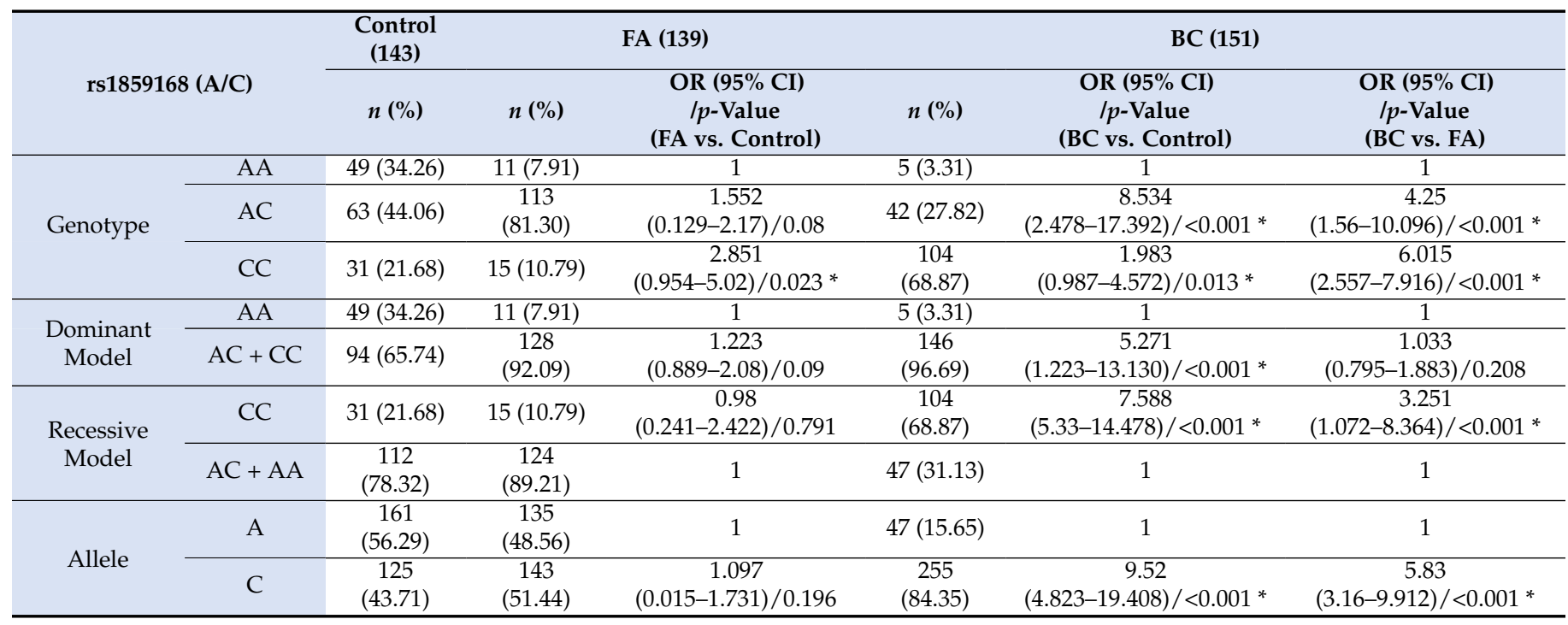

OR: odds ratio and CI: confidence interval. $p$-value is adjusted for age. ${ }^{*}$ Significant at $p<0.05$.

Considering the dominant model, when the AA genotype was taken as a reference, the $\mathrm{AC}+\mathrm{CC}$ genotypes were considerably associated with an increased $\mathrm{BC}$ susceptibility (adjusted OR $=5.271,95 \%$ CI: 1.223-13.130, $p<0.001$ ). Additionally, in the recessive model, the CC genotype was associated with an increased risk of $\mathrm{BC}$ (adjusted OR $=7.588,95 \%$ CI: 5.33-14.478, $p<0.001)$. In addition, the $\mathrm{C}$ allele was associated with a high risk of $\mathrm{BC}$ (adjusted OR $=9.52,95 \%$ CI: 4.823-19.408, $p<0.001$ ). 
More importantly, comparing patients with $\mathrm{BC}$ against those with FA, the CC genotype proved to be strongly associated with an increased incidence of $\mathrm{BC}$ (adjusted OR $=6.015$, 95\% CI: 2.557-7.916, $p<0.001$ ), while the AC genotype was revealed to be significantly low in patients with BC (adjusted OR $=4.25,95 \%$ CI: 1.56-10.096, $p<0.001$ ). Besides, when considering the recessive model, rs1859168 polymorphism was associated with a high risk of $\mathrm{BC}$ (adjusted OR $=3.251,95 \%$ CI: 1.072-8.364, $p<0.001$ ). In addition, the frequency of the $\mathrm{C}$ allele was notably elevated in $\mathrm{BC}$ with respect to FA patients (adjusted $\mathrm{OR}=5.83$, 95\% CI: 3.16-9.912, $p<0.001$ ).

However, no statistical differences were present between the patients with FA and the controls regarding the genotypes and allelic distribution of rs1859168, except that the CC genotype was associated with a low risk of FA (adjusted OR $=2.851,95 \%$ CI: $0.954-5.02$, $p=0.023)$.

\subsection{HOTTIP and miR-615-3p Expression Levels in the Serum of Patients with BC, FA, and Healthy Controls}

The expression levels of HOTTIP and miR-615-3p in the different studied groups are shown in Figure 1.
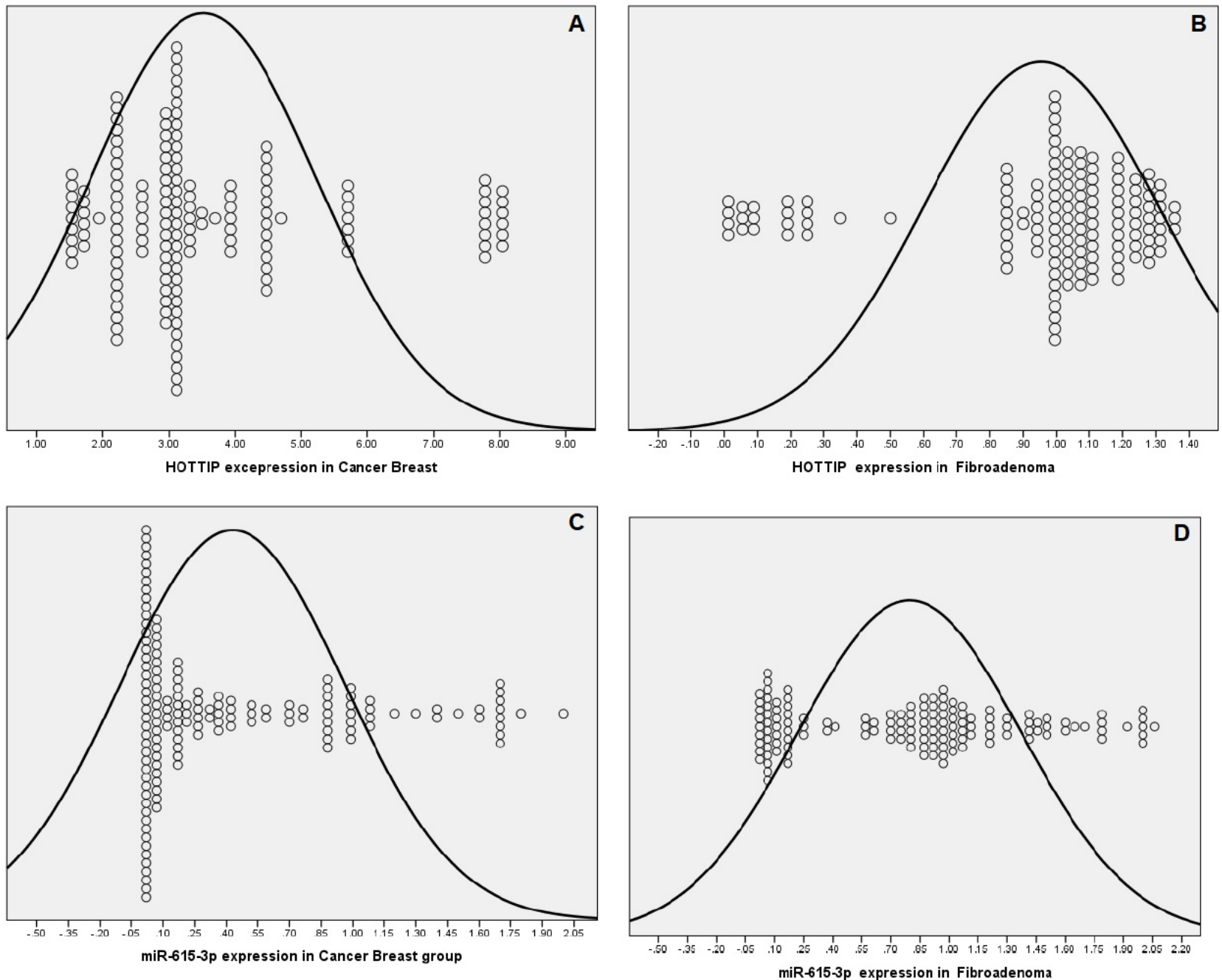

Figure 1. Dot plot representation of the relative expression serum levels of HOTTIP and miR-615-3p in all the study subjects: (A) Relative expression of the fold change of the serum HOTTIP in breast cancer patients. (B) Relative expression of the fold change of the serum HOTTIP in fibroadenoma patients. (C) Relative expression of the fold change of the serum miR-615-3p in breast cancer patients. (D) Relative expression of the fold change of the serum miR-615-3p in fibroadenoma patients. 
HOTTIP had a higher expression (median FC (IQR) was 3.05 (0.09-10.20)), while miR615-3p had a lower expression (median FC (IQR) was $0.19(0.004-2.00)$ ) in the serum of BC patients compared to the healthy ones $(p<0.001$ for HOTTIP and miR-615-3p). In the same way, patients with $B C$ had a significantly increased level of HOTTIP and a significantly decreased level of miR-615-3p relative to patients with FA and, also, relative to the non-BC group (healthy subjects + FA) $(p<0.001$ for all). Through the comparison of the FA cases and control subjects, no marked differences were documented regarding the serum levels of HOTTIP and miR-615-3p (median FC (IQR) of HOTTIP was 1.01 (0.85-1.36), while that for miR-615-3p was $0.89(0.02-2.06))$.

\subsection{The Influence of rs1859168 on the Serum Levels of HOTTIP and miR-615-3p in Patients with $B C$ and $F A$}

We investigated whether rs1859168 was associated with the expression of HOTTIP and miR-615-3p in patients with BC and FA.

Of note, patients with BC who carried the rs 1859168 CC genotype expressed a significantly higher level of HOTTIP (median FC was 4.04, $p<0.001$ ) and a significantly lower level of miR-615-3p (median FC was $0.11, p<0.01$ ) compared with those who carried AA (median FC was 2.04 for the HOTTIP expression, and the median FC was 0.56 for miR-615$3 p$ ). Moreover, HOTTIP was markedly upregulated (median FC was $4.04, p<0.01$ ), while miR-615-3p was markedly downregulated (median FC was $0.11, p<0.01$ ) in BC patients carrying the CC genotype with respect to those with the AC genotype (median FC was 3.1 for the HOTTIP expression, and the median FC was 0.35 for miR-615-3p). In addition, the HOTTIP was drastically elevated in patients with $\mathrm{BC}$ who carried the AC genotype compared to those carrying the AA genotype $(p=0.05)$. The $C$ allele was associated with a higher expression level of HOTTIP and a lower expression of miR-615-3p relative to the A allele in patients with BC (median FC was 3.5, $p<0.001$ for HOTTIP, and the median FC was $0.19, p=0.004$ for miR-615-3p).

Conversely, no significant differences were detected regarding the expression of HOTTIP and miR-615-3p in different genotypes of rs1859168 in patients with FA (Figure 2).

3.5. Associations between the rs1859168 Genotypes, Alleles, Laboratory Data, and Clinical and Pathological Features of Patients with BC

Next, we assessed the relations between the different genotypes and alleles of rs1859168 and the clinicopathological data among the BC cases (Table 3).

Table 3. Genotype and allele frequencies of rs1859168 according to the clinical characteristics of the patients with BC.

\begin{tabular}{|c|c|c|c|c|c|c|}
\hline Parameters & $\begin{array}{c}\mathrm{CC} \\
n(\%)\end{array}$ & $\begin{array}{c}\mathrm{AC}+\mathrm{AA} \\
n(\%)\end{array}$ & OR (95\% CI), $p$-Value & $\begin{array}{c}\mathrm{C} \\
n(\%)\end{array}$ & $\begin{array}{c}\mathrm{A} \\
n(\%)\end{array}$ & OR $(95 \%$ CI), $p$-Value \\
\hline \multicolumn{7}{|l|}{ Age } \\
\hline$<35$ & $48(46.15)$ & $25(53.19)$ & 1 & $98(32.45)$ & $27(8.94)$ & 1 \\
\hline$\geq 35$ & $56(53.85)$ & $22(46.81)$ & $0.522(0.254-1.954), 0.301$ & 157 (50.99) & $20(6.62)$ & 0.339 (0.187-1.09), 0.661 \\
\hline \multicolumn{7}{|l|}{ Family history } \\
\hline No & $29(27.88)$ & $27(57.45)$ & 1 & $188(62.25)$ & $22(7.28)$ & 1 \\
\hline Yes & $75(72.12)$ & $20(42.55)$ & $3.307(1.982-6.148), 0.02$ * & $67(22.20)$ & $25(8.27)$ & $2.359(1.152-3.558), 0.04^{*}$ \\
\hline \multicolumn{7}{|l|}{ History of HTN } \\
\hline No & $89(85.85)$ & 37 (78.72) & 1 & $137(45.36)$ & $19(6.29)$ & 1 \\
\hline Yes & $15(14.15)$ & $10(27.28)$ & $0.528(0.175-0.899) 0.537$ & $118(39.07)$ & $28(9.28)$ & $0.562(0.357-1.076), 0.09$ \\
\hline \multicolumn{7}{|l|}{ History of DM } \\
\hline No & $87(83.65)$ & $39(82.98)$ & 1 & $146(48.35)$ & $30(9.93)$ & 1 \\
\hline Yes & $17(16.35)$ & $8(17.12)$ & $0.492(0.119-0.741) 0.357$ & 109 (36.09) & $17(5.63)$ & $0.341(0.048-0.834) 0.62$ \\
\hline \multicolumn{7}{|l|}{ Menstrual history } \\
\hline Pre. (regular) & $10(9.62)$ & $14(29.79)$ & 1 & $31(10.26)$ & $14(4.63)$ & 1 \\
\hline Pre. (irregular) & $15(14.42)$ & $11(23.41)$ & $0.293(0.108-0.458) 0.803$ & $42(13.91)$ & $8(2.65)$ & $0.338(0.147-0.695) 0.233$ \\
\hline Postmenopausal & $79(75.96)$ & $22(46.80)$ & $1.52(0.684-3.01) 0.05^{*}$ & $182(60.27)$ & $25(8.28)$ & $0.553(0.277-0.830) 0.426$ \\
\hline \multicolumn{7}{|l|}{ Contraception } \\
\hline No & $35(33.65)$ & $13(27.66)$ & 1 & $98(32.45)$ & $15(4.97)$ & 1 \\
\hline Yes & $69(66.34)$ & $34(82.34)$ & $0.553(0.179-0.893) 0.558$ & $157(51.99)$ & $32(10.59)$ & $0.835(0.312-1.078) 0.391$ \\
\hline
\end{tabular}


Table 3. Cont.

\begin{tabular}{|c|c|c|c|c|c|c|}
\hline Parameters & $\begin{array}{c}\mathrm{CC} \\
n(\%)\end{array}$ & $\frac{\mathrm{AC}+\mathrm{AA}}{n(\%)}$ & OR (95\% CI), $p$-Value & $\begin{array}{c}\mathrm{C} \\
n(\%) \\
\end{array}$ & $\begin{array}{c}\mathrm{A} \\
n(\%)\end{array}$ & OR $(95 \% \mathrm{CI}), p$-Value \\
\hline \multicolumn{7}{|l|}{ Type Of Tumor } \\
\hline Invasive Duct II & $79(75.96)$ & $38(80.85)$ & 1 & $205(67.88)$ & $30(9.94)$ & 1 \\
\hline Invasive Duct III & $20(19.23)$ & 8 (17.02) & $0.298(0.113-0.449) 0.469$ & $43(14.24)$ & $12(3.97)$ & $0.229(0.173-0.501) 0.372$ \\
\hline $\begin{array}{c}\text { Invasive Lobular } \\
\text { II } \\
\end{array}$ & $5(4.81)$ & $1(2.13)$ & $0.187(0.097-0.384) 0.834$ & $7(2.32)$ & $5(1.65)$ & $0.308(0.119-0.486) 0.421$ \\
\hline \multicolumn{7}{|l|}{ T classification } \\
\hline T2 & 59 (56.73) & $30(63.83)$ & 1 & $118(39.07)$ & $21(6.96)$ & 1 \\
\hline T3 & $45(43.27)$ & $17(36.17)$ & $1.334(0.886-3.442) 0.05$ * & $137(45.36)$ & $26(8.61)$ & $2.462(1.95-6.087) 0.007^{*}$ \\
\hline \multicolumn{7}{|l|}{ N classification } \\
\hline N1 & $11(10.57)$ & $11(23.40)$ & 1 & $28(9.27)$ & $15(4.97)$ & 1 \\
\hline $\mathrm{N} 2$ & 54 (51.93) & 34 (72.35) & $0.852(0.259-1.097) 0.09$ & $123(40.73)$ & $20(6.62)$ & $2.335(1.85-5.553) 0.008^{*}$ \\
\hline N3 & $39(37.50)$ & $2(4.25)$ & $0.519(0.456-0.82) 0.13$ & $104(34.44)$ & $12(3.97)$ & $1.86(0.943-3.421) 0.05^{*}$ \\
\hline \multicolumn{7}{|l|}{ TNM staging } \\
\hline II & $(87.69)$ & $13(27.65)$ & 1 & $23(7.61)$ & $32(10.60)$ & 1 \\
\hline III & $96(92.31)$ & $34(72.35)$ & $2.36(1.941-4.58)$ & $232(76.82)$ & $15(4.97)$ & $2.087(1.246-6.02) 0.01$ * \\
\hline \multicolumn{7}{|l|}{ ER/PR } \\
\hline Positive & $25(24.04)$ & $10(21.28)$ & 1 & $77(25.50)$ & $15(4.97)$ & 1 \\
\hline Negative & $79(75.96)$ & $37(78.72)$ & $0.899(0.379-1.09) 0.175$ & $178(58.94)$ & $32(10.59)$ & $1.258(0.689-3.08) 0.03^{*}$ \\
\hline \multicolumn{7}{|l|}{ Tumor Size } \\
\hline$<5 \mathrm{~cm}$ & $47(45.19)$ & $32(68.08)$ & 1 & $89(29.47)$ & $19(6.29)$ & 1 \\
\hline$>5 \mathrm{~cm}$ & $57(54.81)$ & $15(31.92)$ & $0.233(0.183-0.506) 0.277$ & 166 (54.97) & $28(9.27)$ & $0.324(0.177-0.526) 0.23$ \\
\hline
\end{tabular}

BC: Breast Cancer, FA: Fibroadenoma, DM: Diabetes mellitus, ER/PR: Estrogen Receptor/Progesterone Receptor, OR: odds ratio, and CI: confidence interval. $p$-value is adjusted for age. ${ }^{*}$ Significant at $p<0.05$.
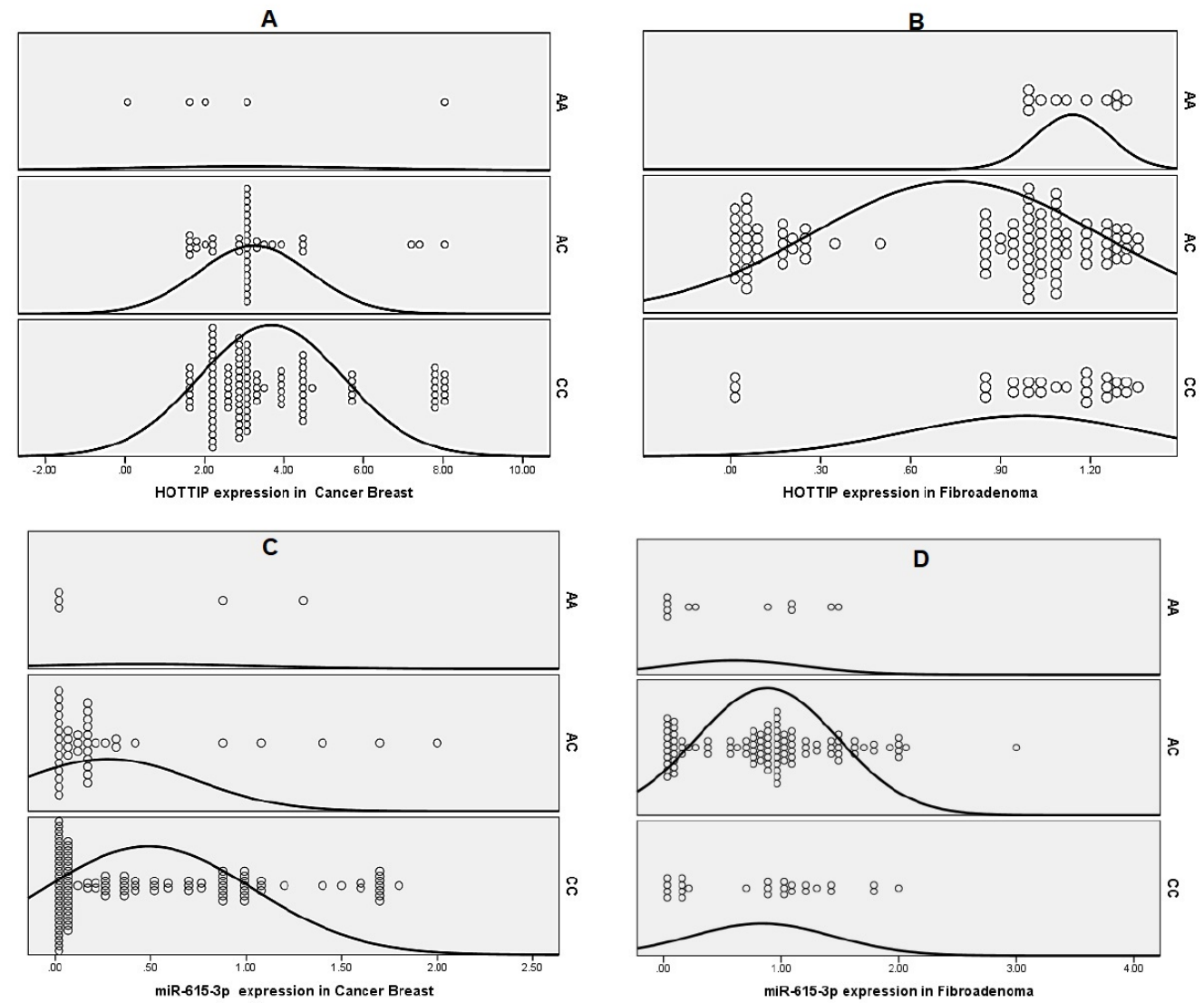

Figure 2. Dot plot representation of the effect of HOTTIP (rs1859168) polymorphism on the expression of serum HOTTIP and miR-615-3p in patients with BC and FA. (A) Relative expression of the fold change of the serum HOTTIP in different genotypes of rs1859168 in patients with breast cancer. (B) Relative expression of the fold change of the serum HOTTIP in different genotypes of rs1859168 in patients with fibroadenoma. (C) Relative expression of the fold change of the serum miR-615-3p in different genotypes of rs1859168 in patients with breast cancer. (D) Relative expression of the fold change of the serum miR-615-3p in different genotypes of rs1859168 in patients with fibroadenoma. 
The incidence of the CC genotype and $C$ allele was increased in individuals who had a positive family history of $\mathrm{BC}$ compared with the $\mathrm{AC}+\mathrm{AA}$ genotype or A allele, respectively (adjusted OR $=3.307,95 \%$ CI: $1.982-6.148, p=0.02$ and adjusted $\mathrm{OR}=2.359$, 95\% CI: 1.152-3.558, $p=0.04$, respectively).

Regarding the T classification of TNM staging, BC patients with the CC genotype and/or the $\mathrm{C}$ allele were more at risk of developing $\mathrm{T} 3$ than those with the $\mathrm{AC}+\mathrm{AA}$ genotype or A allele, respectively (adjusted OR $=1.334,95 \%$ CI: $0.886-3.442, p=0.05$ and adjusted OR $=2.462,95 \%$ CI: $1.95-6.087, p=0.007$, respectively).

Compared with the A allele, the frequency of the $\mathrm{C}$ allele was markedly related to developing N2 and N3 of TNM staging with respect to N1 (adjusted OR $=2.335,95 \%$ CI: $1.85-5.553, p=0.008$ and adjusted $\mathrm{OR}=1.86,95 \% \mathrm{CI}$ : 0.943-3.421, $p=0.05$, respectively).

Interestingly, $\mathrm{BC}$ patients carrying the $\mathrm{C}$ allele were at more risk of developing stage III than stage II, according to the TNM staging (adjusted OR $=2.087,95 \%$ CI: $1.246-6.02$, $p=0.01)$. In addition, compared with the A allele, the $C$ allele was significantly associated with ER/PR positivity (adjusted OR $=1.258,95 \%$ CI: $0.689-3.08, p=0.03$ ).

\subsection{HOTTIP and miR-615-3p Expression Levels in Relation to the Pathological Features and Clinical Parameters in Patients with BC}

Table 4 shows the median expression of HOTTIP and miR-615-3p in BC patients classified by different clinicopathological features.

Table 4. Differences in the HOTTIP and miR-615-3p serum expression levels in relation to the clinical and pathological features in BC patients.

\begin{tabular}{|c|c|c|c|c|}
\hline \multicolumn{2}{|c|}{ Parameters } & $\begin{array}{l}\text { HOTTIP Median } \\
\text { (IQR) }\end{array}$ & $\begin{array}{c}\text { miR-615-3p } \\
\text { Median (IQR) }\end{array}$ & $p$-Value \\
\hline \multirow{2}{*}{ Age } & $<35$ & $3.7(0.81-8.02)$ & $0.35(0.02-2.00)$ & \multirow{2}{*}{$0.04^{*, a}, 0.003 *, b$} \\
\hline & $\geq 35$ & $4.02(0.73-10.1)$ & $0.05(0.004-1.18)$ & \\
\hline \multirow{2}{*}{ Family history } & $\overline{\text { Yes }}$ & $6.08(1.02-10.2)$ & $0.14(0.004-1.76)$ & \multirow{2}{*}{$<0.001^{*, \mathrm{a}}, 0.02 *, \mathrm{~b}$} \\
\hline & No & $2.01(0.14-3.57)$ & $0.52(0.01-2.00)$ & \\
\hline \multirow{2}{*}{$\begin{array}{c}\text { History } \\
\text { ofHypertension }\end{array}$} & Yes & $3.1(0.81-10.05)$ & $0.20(0.004-0.92)$ & \multirow{2}{*}{$0.194^{a}, 0.533^{b}$} \\
\hline & No & $4.04(0.07-8.05)$ & $0.27(0.05-2.00)$ & \\
\hline \multirow{2}{*}{ History of DM } & Yes & $3.87(0.75-8.15)$ & $1.89(0.01-0.88)$ & \multirow{2}{*}{$0.567^{a}, 0.287^{b}$} \\
\hline & No & $3.8(0.16-10.20)$ & $0.25(0.004-2.00)$ & \\
\hline \multirow{3}{*}{ Menstrual history } & $\begin{array}{l}\text { Premenopausal } \\
\text { (regular) }\end{array}$ & $2.9(0.09-6.04)$ & $0.27(0.004-1.92)$ & \multirow{3}{*}{$0.338^{a}, 0.09^{b}$} \\
\hline & $\begin{array}{l}\text { Premenopausal } \\
\quad \text { (irregular) }\end{array}$ & $2.5(0.185-8.45)$ & $0.19(0.03-2.00)$ & \\
\hline & Postmenopausal & $3.08(0.09-10.06)$ & $0.24(0.07-1.81)$ & \\
\hline \multirow{2}{*}{$\begin{array}{c}\text { Hormonal } \\
\text { Contraceptive }\end{array}$} & Yes & $3.1(0.28-6304)$ & $0.21(0.004-0.179)$ & \multirow{2}{*}{$0.433^{a}, 0.294^{b}$} \\
\hline & No & $2.9(0.98-10.2)$ & $0.18(0.001-2.00)$ & \\
\hline \multirow{3}{*}{ type of tumor } & invasive duct ii & $3.01(0.65-7.05)$ & $0.18(0.004-1.89)$ & \multirow{3}{*}{$0.663^{\mathrm{a}}, 0.138^{\mathrm{b}}$} \\
\hline & invasive duct iii & $2.09(0.93-9.05)$ & $0.20(0.009-1.92)$ & \\
\hline & invasive lobular ii & $2.87(0.73-10.02)$ & $0.25(0.01-2.00)$ & \\
\hline \multirow{2}{*}{$\mathrm{T}$ classification } & $\mathrm{T} 2$ & $3.5(0.99-8.55)$ & $0.19(0.009-1.89)$ & \multirow{2}{*}{$0.731^{a}, 0.197^{b}$} \\
\hline & T3 & $2.9(0.08-10.01)$ & $0.22(0.004-2.00)$ & \\
\hline \multirow{3}{*}{$\mathrm{N}$ classification } & N1 & $3.09(0.82-6.72)$ & $0.18(0.01-1.89)$ & \multirow{3}{*}{$0.208^{a}, 0.342^{b}$} \\
\hline & N2 & $3.01(0.19-10.05)$ & $0.24(0.004-1.92)$ & \\
\hline & N3 & $2.89(0.97-7.85)$ & $0.22(0.09-2.00)$ & \\
\hline \multirow{2}{*}{ TNM staging } & II & $3.5(0.07-10.05)$ & $0.25(0.01-1.76)$ & \multirow{2}{*}{$0.70^{a}, 0.05^{*}, \mathrm{~b}$} \\
\hline & III & $3.05(0.99-8.55)$ & $0.18(0.004-2.00)$ & \\
\hline \multirow{2}{*}{$\mathrm{ER} / \mathrm{PR}$} & Positive & $4.04(0.09-10.2)$ & $0.18(0.004-1.53)$ & \multirow{2}{*}{$0.02^{*, a}, 0.03^{*, b}$} \\
\hline & Negative & $1.98(0.93-6.08)$ & $0.29(0.09-2.00)$ & \\
\hline \multirow{2}{*}{ Tumor Size } & $<5 \mathrm{~cm}$ & $2.75(0.9-8.55)$ & $0.19(0.004-189)$ & \multirow{2}{*}{$0.297^{a}, 0.439^{b}$} \\
\hline & $>5 \mathrm{~cm}$ & $3.90(1.2-10.2)$ & $0.21(0.009-2.00)$ & \\
\hline
\end{tabular}

BC: Breast Cancer, FA: Fibroadenoma, DM: Diabetes mellitus, ER/PR: Estrogen Receptor/Progesterone Receptor, and IQR: Interquartile range. ${ }^{a}: p$-value for HOTTIP and ${ }^{b}: p$-value for miR-615-3p. ${ }^{*}$ Significant at $p<0.05$. 
There was a significant overexpression of HOTTIP and downregulation of miR-615-3p in patients with $\mathrm{BC}$ whose ages $\geq 35$ ( $p=0.04$ and $p=0.003$, respectively). Moreover, there was a considerable elevation of the HOTTIP level and a significant decrease in miR-615-3p in patients with $\mathrm{BC}$ with a positive family history, as well as in patients who had positive ER/PR $(p<0.05)$. Besides, a marked decrease in the miR-615-3p expression was noted in the present research in patients who developed grade III diseases according to the TNM staging than those with grade II $(p=0.05)$.

In contrast, no marked association was detected between the HOTTIP or miR-615-3p expression levels and other clinicopathological features.

\subsection{Correlation between the Serum HOTTIP and miR-615-3p Levels in Patients with BC}

The Spearman analysis revealed a negative correlation between the expression level of HOTTIP and miR-615-3p in patients with BC $(r=-0.631$ and $p<0.001)$ (Figure 3).

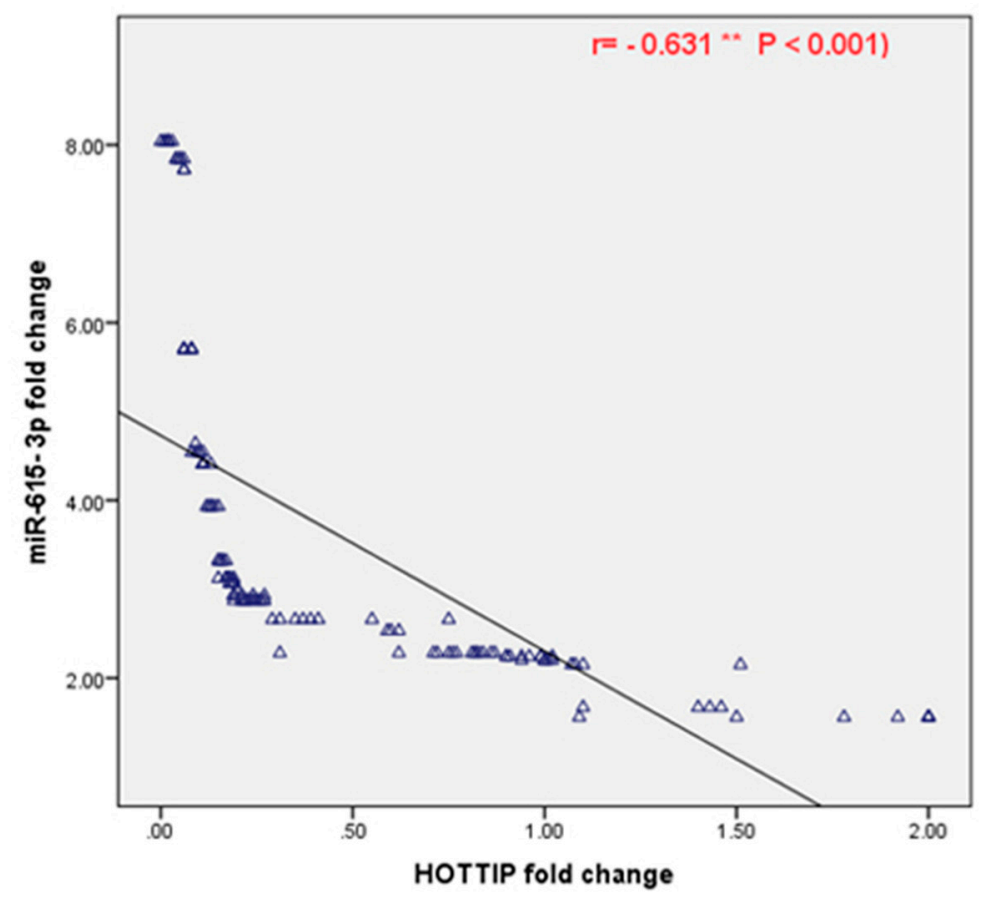

Figure 3. Spearman correlation between the HOTTIP and miR-615-3p serum expression levels in patients with BC. ${ }^{* *}$ Significant at $p<0.001$.

\subsection{Evaluation of Serum HOTTIP and miR-615-3p as Diagnostic Biomarkers of BC}

To assess the accuracy of the serum HOTTIP and miR-615-3p for the early detection of $B C$, we conducted receiver operating characteristic (ROC) curves to distinguish BC patients from those with FA. For the serum HOTTIP, the AUC was 0.613 (95\% confidence interval: $0.545-0.680$ ), and the sensitivity and specificity were $91.2 \%$ and $87.95 \%$, respectively. Likewise, the AUC concerning the serum miR- 615-3p was 0.816 (95\% confidence interval: $0.763-0.869$ ), with a sensitivity and specificity of $89.8 \%$ and $98.5 \%$, respectively (Table 5 and Figure 4).

A ROC curve was performed to find out whether the serum HOTTIP and miR-615-3p could differentiate $\mathrm{BC}$ from those without $\mathrm{BC}$ (FA+ healthy persons). Concerning HOTTIP, the AUC was 0.615 (95\% confidence interval: $0.540-0.689)$, and the sensitivity and specificity were $94.5 \%$ and $89.5 \%$, respectively. Furthermore, miR-615-3p showed an AUC of 0.841 (95\% confidence interval: $0.793-0.888$ ), and the sensitivity and specificity were $90.4 \%$ and $95.6 \%$, respectively (Table 5 and Figure 5 ). 
Table 5. ROC curve of the serum HOTTIP and miR-615-3p.

\begin{tabular}{|c|c|c|c|c|c|}
\hline Variable & AUC (95\% CI) & $p$-Value & Sensitivity & Specificity & Total Accuracy \\
\hline HOTTIP (BC vs. FA) & $\begin{array}{c}0.613 \\
(0.545-0.680)\end{array}$ & $0.001 *$ & $91.2 \%$ & $87.95 \%$ & 89.57 \\
\hline $\begin{array}{l}\text { miR-615-3p } \\
\text { (BC vs. FA) }\end{array}$ & $\begin{array}{c}0.816 \\
(0.763-0.869)\end{array}$ & $<0.001 *$ & $89.8 \%$ & $98.5 \%$ & 94.15 \\
\hline HOTTIP (BC vs. control + FA) & $\begin{array}{c}0.615 \\
(0.540-0.689) \\
\end{array}$ & $<0.001 *$ & $94.5 \%$ & $89.5 \%$ & 90.00 \\
\hline $\begin{array}{c}\text { miR-615-3p } \\
(\mathrm{BC} \text { vs. control + FA) }\end{array}$ & $\begin{array}{c}0.841 \\
(0.793-0.888)\end{array}$ & $<0.001 *$ & $90.4 \%$ & $95.6 \%$ & 93 \\
\hline
\end{tabular}

BC: Breast Cancer, FA: Fibroadenoma, AUC: area under the curve, and CI: confidence interval. * Significant at $p<0.05$.

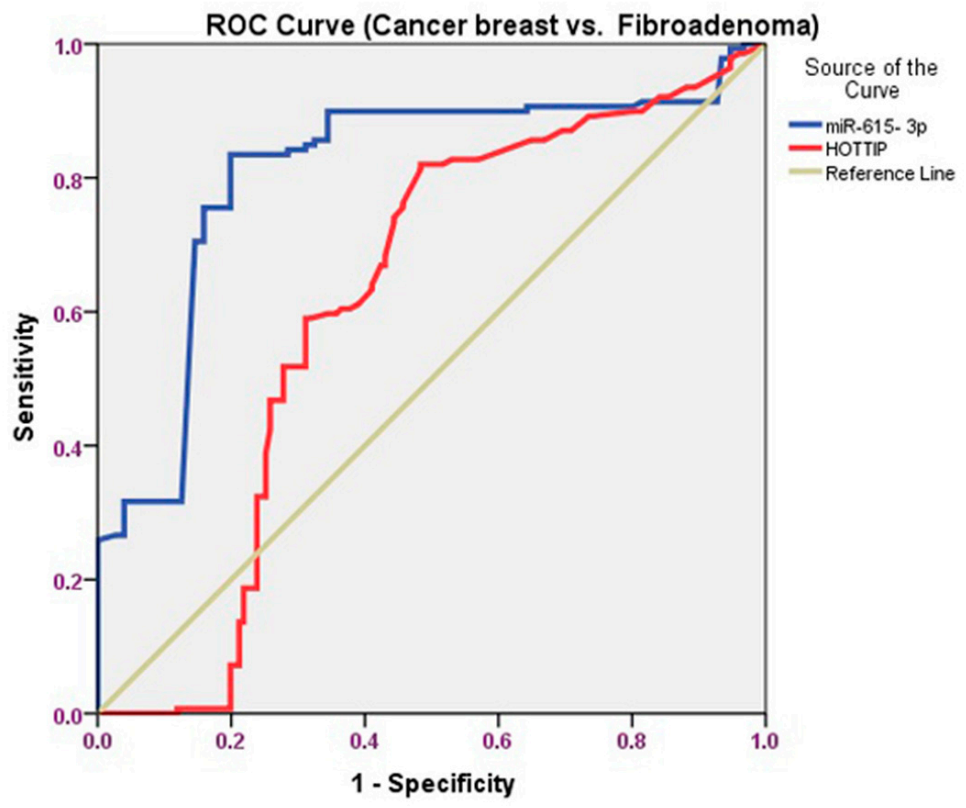

Figure 4. ROC curve analysis of the serum HOTTIP and miR-615-3p for differentiating BC patients from patients with FA.

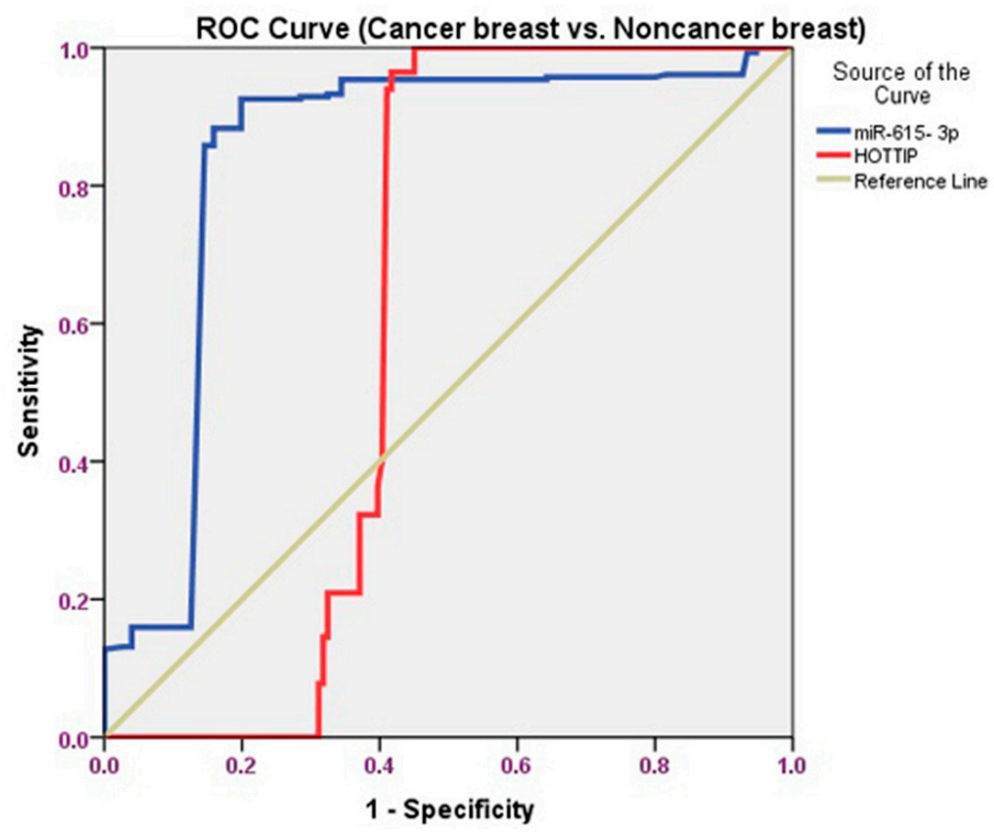

Figure 5. ROC curve analysis of the serum HOTTIP and miR-615-3p for distinguishing patients with $\mathrm{BC}$ against those without $\mathrm{BC}$ (FA+ healthy persons). 


\section{Discussion}

Breast cancer is one of diseases that occurs frequently in Egypt [20]. The early diagnosis of $B C$ is associated with a low mortality rate [21]. Surgery is valuable in treating early $\mathrm{BC}$, though recurrence might occur in several patients [22]. Therefore, discovering novel noninvasive biomarkers has become an urgent necessity to help with an early diagnosis and to develop novel therapeutic targets.

MiRNAs and lncRNAs are two classes of noncoding RNAs verified to play a necessary role in the pathogenesis of numerous cancers, including BC $[9,13]$. Furthermore, the evaluation of noncoding RNAs in the serum has emerged as a novel noninvasive biomarker of BC $[23,24]$. To date, many studies have suggested that lncRNA polymorphisms could alter the function and expression of those IncRNAs influencing the susceptibility to cancers $[10,11]$. However, the association of rs 1859168 in HOTTIP with BC susceptibility has not been addressed yet.

In this study, we revealed that the $\mathrm{CC}$ genotype and $\mathrm{C}$ allele were strongly linked to an increased risk of $\mathrm{BC}$ compared with the control or FA groups, while the AC genotype was associated with a decreased incidence of $B C$ relative to healthy individuals or patients with FA.

In recent years, few researchers have reported an association between rs1859168 in HOTTIP and the risk of cancers. Rs1859168 was hypothesized to modulate the expression of HOTTIP through influencing the transcription factor-binding sites. In addition, rs1859168 was reported to affect the folding and function of HOTTIP [25].

Gong et al. revealed that individuals who carry the AA genotype might be at a decreased risk for lung cancer [25]. Additionally, Ali et al. demonstrated a significant association between rs1859168 polymorphism (CC genotype and C allele) and susceptibility to colorectal cancer in the Egyptian population, which is similar to our results [26].

In contrast, it was observed that rs1859168 polymorphism in HOTTIP was associated with a decreased risk of pancreatic cancer; the authors found that the $C$ allele of rs1859168 was markedly related to a reduced susceptibility to PC [12]. Furthermore, Duan and his colleagues suggested that the HOTTIP SNP rs1859168 was notably associated with a reduced gastric cancer susceptibility in the Chinese population [9]. However, the rs1859168 polymorphism was not related to the incidence of ovarian cancer in the research that was performed by Richards et al. [27].

In our study, we showed that the HOTTIP level is markedly upregulated, while miR$615-3 p$ is markedly reduced in the serum of patients with BC compared to the control individuals or patients with FA.

Our findings were in-line with the results of Sun et al., who determined that HOTTIP is significantly upregulated in the breast cancer cell line and related to BC proliferation, migration, and apoptosis via the modulation of the expression of HOXA11 [28]. Similarly, it was documented that the BC tissue samples had elevated expression levels of HOTTIP, and they were associated with a grim prognosis [8].

In previous studies, it has been verified that the knockdown of HOTTIP resulted in reduced cell proliferation and attenuated metastasis in hepatocellular carcinoma and in non-small cell lung cancer [29,30]. Additionally, two other studies showed the association between the elevated expression level of HOTTIP and each of dismal prognosis and metastasis in PC and hepatocellular carcinoma [31,32].

Accumulating evidence has explained that lncRNAs have a major role in tumor progression via targeting miRNAs [33]. It was shown that HOTTIP binds to miR-615, resulting in its downregulation $[16,34]$. Increasing studies have indicated the implication of miR-615 in numerous cancers, as it was verified to be a tumor suppressor [13-15]. However, to the best of our knowledge, our study is the first to assess the miR-615-3p expression in the serum of patients with BC.

The results from our series are in agreement with Bai et al., who revealed that miR615 was significantly repressed in BC tissues and inhibited the expression of AKT2 [14]. However, the upregulation of miR-615-3p in BC cells was shown. It was elucidated 
that miR-615-3p promotes the metastasis and epithelial-mesenchymal transition through targeting Protein Interacting with C Kinase -1 (PICK1) [35]. Interestingly, the miR-615$3 p$ expression level proved to be increased in the luminal B HER 2-positive cases, while decreased in HER2-enriched BC [36].

More importantly, our results indicated that there is a negative correlation between the serum expression level of HOTTIP and that of miR-615-3p. Consistent with our hypothesis, Wang et al. reported a negative correlation between the aforementioned noncoding RNAs in renal carcinoma [16]. Additionally, Shi and his colleagues confirmed that HOTTIP is negatively correlated to miR-615-3p in non-small cell lung cancer cells [34].

The polymorphisms in lncRNAs not only influence the levels of mature lncRNAs but also affect their target gene expression. Therefore, we analyzed, for the first time, whether HOTTIP and miR-615-3p were changed significantly among the different genotypes of rs1859168 in patients with BC.

We determined that the $C C$ genotype and $C$ allele were related to an elevated expression of HOTTIP and a decreased expression of miR-615-3p in BC.

In contrast, the levels of HOTTIP and miR-615-3p were not significantly changed among the different genotypes and allele distribution in FA. This is in contract with the study performed by $\mathrm{Hu}$ et al., in which the $\mathrm{C}$ allele of rs1859168 was determined to be related to the decreased levels of HOTTIP in PC [12].

Our current study reported that BC patients with the CC genotype and or C allele (which were related to an elevated expression of HOTTIP) were more at risk of developing $\mathrm{T} 3$ than those with the AC + AA genotype or A allele, respectively. Furthermore, the frequency of the $C$ allele was markedly related to developing N2 and N3 of TNM staging with respect to $\mathrm{N} 1$. In addition, $\mathrm{BC}$ patients carrying the $\mathrm{C}$ allele were more at risk of developing stage III than stage II, according to the TNM staging.

Our results are in agreement with previous research that demonstrated the association between high levels of HOTTIP with a bad prognosis and advanced TNM staging in BC [8]. Similarly, Wang et al. verified that upregulated HOTTIP is related to a higher clinical stage, tumor size, metastasis lymph node, and worse clinical stage in renal cell carcinoma [16].

The ROC curve was carried out and proved that serum HOTTIP could be used to discriminate patients with $\mathrm{BC}$ from the FA group and those without $\mathrm{BC}$ (FA+ healthy persons).

Future studies are needed to clarify the mechanism of how rs1859168 influences BC pathogenesis, as well as to explain its links with HOTTIP and miR-615-3p expression in other ethnic groups. In addition, the exact role of the aforementioned noncoding RNAs in BC should be investigated and clarified. The present results should be confirmed in further, larger research.

To sum up, our current findings indicated that the rs 1859168 genetic variants were related to the increased incidence of BC. Additionally, our results suggested that serum HOTTIP and miR-615-3p may have indicative potential to predict BC and may be used as targets for $\mathrm{BC}$ treatment. Furthermore, we recognized a negative correlation between HOTTIP and miR-615-3p in the serum of patients with BC. Finally, we verified that the CC genotype and $C$ allele were associated with high levels of HOTTIP and low levels of miR-615-3p in patients with BC.

Author Contributions: M.N.A. and M.Z. performed the patient examination and treatments; O.G.S., S.R.M., O.O.A., N.K.A., O.M.Z., and N.F.H. performed the biochemical assays; H.M.E., A.A.K., N.A.A. and A.A.A.A. interpreted the data; and O.O.A. and N.A.A. were the major contributors in writing the manuscript. All authors have agreed to publish this paper in your journal, and they confirm this manuscript is not under publication in any other journal. All authors have read and agreed to the published version of the manuscript.

Funding: This research received no external funding.

Institutional Review Board Statement: The study was conducted according to the guidelines of the Declaration of Helsinki and approved by Fayoum University Local Ethics Committee (protocol code R168). 
Informed Consent Statement: Informed consent was obtained from all subjects involved in the study.

Data Availability Statement: The data that support the findings of this study are not available due to patients confidentiality.

Acknowledgments: We thank all the medical and paramedical staff who helped in the achievement of this work.

Conflicts of Interest: The authors declare no conflict of interest.

\section{References}

1. Siegel, R.L.; Miller, K.D.; Jemal, A. Cancer statistics, 2017. CA Cancer J. Clin. 2017, 67, 7-30. [CrossRef]

2. Koboldt, D.C.; Fulton, R.S.; McLellan, M.D.; Schmidt, H.; Kalicki-Veizer, J.; McMichael, J.F.; Fulton, L.L.; Dooling, D.J.; Ding, L.; Mardis, E.R.; et al. Comprehensive molecular portraits of human breast tumours. Nature 2012, 490, 61-70.

3. Sidaway, P. Breast cancer: LAG3 expression indicates favourable outcomes. Nat. Rev. Clin. 2017, 14, 712.

4. Gutschner, T.; Diederichs, S. The hallmarks of cancer: A long non-coding RNA point of view. RNA Biol. 2012, 9, 703-719. [CrossRef]

5. Valadkhan, S.; Gunawardane, L.S. LncRNA-mediated regulation of the interferon response. Virus Res. 2016, 212, 127-136. [CrossRef] [PubMed]

6. Wang, K.C.; Yang, Y.W.; Liu, B.; Sanyal, A.; Corces-Zimmerman, R.; Chen, Y.; Lajoie, B.R.; Protacio, A.; Flynn, R.A.; Gupta, R.A.; et al. A long noncoding RNA maintains active chromatin to coordinate homeoticgene expression. Nature 2011, 472, 120-124. [CrossRef]

7. Lian, Y.; Cai, Z.; Gong, H.; Xue, S.; Wu, D.; Wang, K. HOTTIP: A critical oncogenic long non-coding RNA in human cancers. Mol. Biosyst. 2016, 12, 3247-3253. [CrossRef] [PubMed]

8. Yang, Y.; Qian, J.; Xiang, Y.; Chen, Y.; Qu, J. The prognostic value of long noncoding RNA HOTTIP on clinical outcomes in breast cancer. Oncotarget 2017, 8, 6833-6844. [CrossRef]

9. Duan, F.; Jiang, J.; Song, C.; Wang, P.; Ye, H.; Dai, L.; Zhang, J.; Wang, K.F. Functional long non-coding RNAsassociated with gastric cancer susceptibility and evaluation of the epidemiological efficacy in a central Chinese population. Gene 2018, 646, 227-233. [CrossRef]

10. Tao, R.; Hu, S.; Wang, S.; Zhou, X.; Zhang, Q.; Wang, C.; Zhao, X.; Zhou, W.; Zhang, S.; Li, C.; et al. Association between indel polymorphism in the promoter region of lncRNA GAS5 and the risk of hepatocellular carcinoma. Carcinogenesis 2015, 36, 1136-1143. [CrossRef]

11. Pan, W.; Liu, L.; Wei, J.; Ge, Y.; Zhang, J.; Chen, H.; Zhou, L.; Yuan, Q.; Zhou, C.; Yang, M. A functional lncRNA HOTAIR genetic variant contributes to gastric cancersusceptibility. Mol. Carcinog. 2016, 55, 90-96. [CrossRef] [PubMed]

12. Hu, P.; Qiao, O.; Wang, J.; Li, J.; Jin, H.; Li, Z.; Jin, Y. rs1859168 A > C polymorphism regulates HOTTIP expression and reduces risk of pancreatic cancer in a Chinese population. World J. Surg. Oncol. 2017, 15, 155. [CrossRef]

13. Chen, Z.; Wang, X.; Liu, R.; Chen, L.; Yi, J.; Qi, B.; Shuang, Z.; Liu, M.; Li, X.; Li, S.; et al. KDM4B-mediated epigenetic silencing of miRNA-615-5p augments RAB24 to facilitate malignancy of hepatoma cells. Oncotarget 2017, 8, 17712-17725. [CrossRef] [PubMed]

14. Bai, Y.; Li, J.; Li, J.; Liu, Y.; Zhang, B. MiR-615 inhibited cell proliferationand cell cycle of human breast cancer cells by suppressingof AKT2 expression. Int. J. Clin. Exp. Med. 2015, 8, 3801-3808.

15. Gao, W.; Gu, Y.; Li, Z.; Cai, H.; Peng, Q.; Tu, M.; Kondo, Y.; Shinjo, K.; Zhu, Y.; Zhang, J.; et al. miR-615-5p is epigenetically inactivatedand functions as a tumor suppressor in pancreatic ductal adenocarcinoma. Oncogene 2015, 34, 1629-1640. [CrossRef]

16. Wang, Q.; Wu, G.; Zhang, Z.; Tang, Q.; Zheng, W.; Chen, X.; Chen, F.; Li, Q.; Che, X. Long non-coding RNA HOTTIP promotes renal cell carcinomaprogression through the regulation of the miR-615/IGF-2 pathway. Int. J. Oncol. 2018, 53, 2278-2288.

17. Duan, W.; Du, L.; Jiang, X.; Wang, R.; Yan, S.; Xie, Y.; Yan, K.; Wang, Q.; Wang, L.; Zhang, X.; et al. Identification of a serum circulating lncRNA panel for the diagnosis and recurrence prediction of bladder cancer. Oncotarget 2016, 7, 78850-78858. [CrossRef] [PubMed]

18. Shaker, O.G.; Abdelaleem, O.O.; Mahmoud, R.H.; Abdelghaffar, N.K.; Ahmed, T.I.; Said, O.M.; Zaki, O.M. Diagnostic and Prognostic Role of Serum miR-20b, miR-17-3p, HOTAIR, and MALAT1 inDiabetic Retinopathy. Iubmb Life 2019, 71, 310-320. [CrossRef]

19. Livak, K.J.; Schmittgen, T.D. Analysis of relative gene expression data using real-time quantitative PCR and the 2(-DeltaDeltaC(T)) Method. Methods 2001, 25, 402-408. [CrossRef] [PubMed]

20. Ibrahim, A.S.; Khaled, H.M.; Mikhail, N.N.; Baraka, H.; Kamel, H. Cancer incidence in Egypt: Results of the national populationbased cancer registry program. J. Cancer Epidemiol. 2014, 2014, 437971. [CrossRef]

21. Albrand, G.; Terret, C. Early breast cancer in the elderly:assessment and management considerations. Drugs Aging 2008, 25, 35-45. [CrossRef]

22. Langstein, H.N.; Cheng, M.H.; Singletary, S.E.; Robb, G.L.; Hoy, E.; Smith, T.L.; Kroll, S.S. Breast cancer recurrence after immediate reconstruction: Patterns and significance. Plast. Reconstr. Surg. 2003, 111, 712-720. [CrossRef] [PubMed] 
23. McAnena, P.; Tanriverdi, K.; Curran, C.; Gilligan, K.; Jane, E.; Freedman James, A.L.; Brown, M.; Kerin, J. Circulating microRNAs miR-331 and miR-195 differentiate local luminal a from metastatic breast cancer. BMC Cancer 2019, 19, 436. [CrossRef] [PubMed]

24. Ali, M.A.; Shaker, O.G.; Alazrak, M.; AbdelHafez, M.N.; Khalefa, A.A.; Hemeda, N.F.; Abdelmoktader, A.; Ahmed, F.A. Association analyses of a genetic variant in long non-coding RNA MEG3 with breast cancer susceptibility and serum MEG3 expression level in the Egyptian population. Cancer Biomark. 2020, 28, 49-63. [CrossRef] [PubMed]

25. Gong, W.J.; Yin, J.Y.; Li, X.P.; Fang, C.; Xiao, D.; Zhang, W.; Zhou, H.H.; Li, X.; Liu, Z.Q. Association of well-characterized lung cancer lncRNA polymorphisms withlung cancer susceptibility and platinum-based chemotherapy response. Tumour Biol. 2016, 37, 8349-8358. [CrossRef]

26. Ali, M.A.; Shaker, O.G.; Ezzat, E.M.; Gaber, S.N.; Hassan, E.A.; Abdelwahed, M.Y. Association Between rs1859168/HOTTIP Expression Level and Colorectal Cancer and Adenomatous Polyposis Risk in Egyptians. J. Interferon Cytokine Res. 2020, 40, 6. [CrossRef]

27. Richards, E.J.; Permuth-Wey, J.; Li, Y.; Chen, Y.A.; Coppola, D.; Reid, B.M.; Lin, H.Y.; Teer, J.K.; Berchuck, A.; Birrer, M.J.; et al. A functional variant in HOXA11-AS, a novellong non-coding RNA, inhibits the oncogenic phenotype of epithelialovarian cancer. Oncotarget 2015, 6, 34745-34757. [CrossRef] [PubMed]

28. Sun, Y.; Zeng, C.; Gan, S.; Li, H.; Cheng, Y.; Chen, D. LncRNA HOTTIP-Mediated HOXA11 Expression Promotes Cell Growth, Migration and Inhibits Cell Apoptosis in Breast Cancer. Int. J. Mol. Sci. 2018, 19, 472. [CrossRef]

29. Tsang, F.H.; Au, S.L.; Wei, L.; Fan, D.N.; Lee, J.M.; Wong, C.C.; Ng, I.O.; Wong, C.M. Long non-coding RNA HOTTIP is frequently up-regulated in hepatocellular carcinoma and is targeted by tumour suppressive miR-125b. Liver Int. 2015, 35, 1597-1606. [CrossRef]

30. Sang, Y.; Zhou, F.; Wang, D.; Bi, X.; Liu, X.; Hao, Z.; Li, Q.; Zhang, W. Up-regulation of long non-coding HOTTIP functions as an oncogene by regulating HOXA13 in non-small cell lung cancer. Am. J. Transl. Res. 2016, 8, 2022-2032. [PubMed]

31. Li, Z.; Zhao, X.; Zhou, Y.; Liu, Y.; Zhou, Q.; Ye, H.; Wang, Y.; Zeng, J.; Song, Y.; Gao, W.; et al. The long non-coding RNA HOTTIP promotes progression and gemcitabine resistance by regulating HOXA13 in pancreatic cancer. J. Transl. Med. 2015, 13, 84. [CrossRef] [PubMed]

32. Quagliata, L.; Matter, M.S.; Piscuoglio, S.; Arabi, L.; Ruiz, C.; Procino, A.; Kovac, M.; Moretti, F.; Makowska, Z.; Boldanova, T.; et al. Long noncoding RNA HOTTIP/HOXA13 expression is associated with disease progression and predicts outcome in hepatocellular carcinoma patients. Hepatology 2014, 59, 911-923. [CrossRef] [PubMed]

33. Mercer, T.R.; Dinger, M.E.; Mattick, J.S. Long non-coding RNAs: Insights into functions. Nat. Rev. Genet. 2009, 10, 155-159. [CrossRef] [PubMed]

34. Shi, J.; Wang, H.; Feng, W.; Huang, S.; An, J.; Qiu, Y.; Wu, K. Long non-coding RNA HOTTIP promotes hypoxia-induced glycolysis through targeting miR-615-3p/HMGB3 axis in non-small cell lung cancer cells. Eur. J. Pharmacol. 2019, 862, 172615. [CrossRef]

35. Lei, B.; Wang, D.; Zhang, M.; Deng, Y.; Jiang, H.; Li, Y. miR-615-3p promotes the epithelial-mesenchymal transition and metastasis of breast cancer by targeting PICK1/TGFBRI axis. J. Exp. Clin. Cancer Res. 2020, 39, 71. [CrossRef]

36. Souza, K.C.B.; Evangelista, A.F.; Leal, L.F.; Souza, C.P.; Vieira, R.A.; Causin, R.L.; Neuber, A.C.; Pessoa, D.P.; Passos, G.A.S.; Reis, R.M.V.; et al. Identification of Cell-Free Circulating MicroRNAs for the Detection of Early Breast Cancer and Molecular Subtyping. J. Oncol. 2019, 8393769. [CrossRef] [PubMed] 